\title{
A INCIDÊNCIA DE TUBERCULOSE NOS PRESÍDIOS BRASILEIROS: REVISÃO SISTEMÁTICA
}

\author{
THE INCIDENCE OF TUBERCULOSIS IN BRAZILIAN PRISONS: SYSTEMATIC REVIEW
}

\section{Jean Carlos Machado ${ }^{a}$, Jilia Diane Martins Boldorib, Marcelo Dalton Dalmolinc, William Cordeiro de Souzad ${ }^{d}$, Sandro Luiz Bazzanella ${ }^{\mathrm{e}}$, Walter Marcos Knaesel Birknerf, Luis Paulo Gomes Mascarenhas ${ }^{g}$}

\author{
amestrado@unc.br, bjiliamartins@hotmail.com, cmarcelo@unc.br, dprofessor_williamsouza@yahoo.com.br, \\ esandroluizbazzanella@gmail.com, fb-walter@hotmail.com, gmasca58@hotmail.com \\ Universidade do Contestado - Canoinhas (SC), Brasil
}

Data de recebimento do artigo: 12/03/2015

Data de aceite do artigo: 24/09/2015

\section{RESUMO}

Introduçáo: A presença da tuberculose no sistema prisional tem sido descrita como uma ameaça, já que tem maior incidência na população carcerária do que na população em geral. Objetivo: Verificar, através de uma revisão de literatura, as principais razóes dos casos de tuberculose nos presídios brasileiros. Materiais e métodos: Foi realizada uma busca na base de dados dos Periódicos da Capes e Bielefeld Academic Search Engine (BASE) com os termos "tuberculose", "presídio" e "brasileiros". A busca totalizou 34 documentos, dos quais somente 8 foram utilizados para a referida pesquisa. Resultados e conclusáo: A partir dos dados obtidos foi possível observar altas taxas de infecçáo por tuberculose nos presídios brasileiros, baixa informação sobre a doença e precariedade no atendimento dos infectados, além dessa enfermidade apresentar associação com o tempo de permanência na prisão.

Palavras-chave: Tuberculose; presídios; brasileiros.

\section{ABSTRACT}

Introduction: The presence of tuberculosis in the prison system has been described as a threat, once its incidence is higher in the prison population than in the general one. Objective: To verify through a literature review the main reasons for cases of tuberculosis (TB) in Brazilian prisons. Materials and Methods: A search in the Journals database of Capes and Bielefeld Academic Search Engine (BASE) was performed with the words "tuberculosis", "prison" and "Brazilian". The search totaled 34 documents, of which only eight were used for this search. Results and conclusion: From the data obtained we observed high TB infection rates in Brazilian prisons, poor information about the disease and insecurity in the care of those infected, along with an association of this disease with the duration of the stay in prison.

Keywords: Tuberculosis; prisons; Brazilians. 


\section{Introdução}

Aplicada quando do cometimento de um crime, uma vez que a conduta criminosa lesa bens ou interesses juridicamente tutelados, a pena de prisão deve atender a dois objetivos: prevenção geral de crimes, como intimidação que se dirige aos membros da sociedade; e prevenção especial do crime, no sentido de retribuição do mal causado pelo agente que o cometeu, para reeducá-lo ${ }^{1}$.

No Brasil, desde a instalação dos primeiros presídios para a execução das penas de prisão, as precárias condiçóes de saneamento e a completa ausência de atendimento de saúde aos detentos acabaram por acarretar uma alta taxa de mortalidade dos encarcerados. Muito embora não existam muitos registros históricos, não é desarrazoado supor que grande parte dos óbitos seja decorrente da tuberculose $(\mathrm{TB})^{2}$.

A ocorrência da TB está relacionada ao modo de viver e trabalhar dos indivíduos, notadamente sua inserção em um ambiente insalubre e dissociado de uma política de controle da doença, como ocorre nos presídios brasileiros. Por algum tempo acreditava-se que ao início do século XXI a TB estaria erradicada. O surgimento do HIV e da Aids alterou essa percepçáo ${ }^{3}$.

No sistema prisional, a TB tem sido considerada um problema de saúde pública, já que sua incidência é maior entre os presos do que na populaçấo em geral ${ }^{4}$. Vale ressaltar que a TB é uma doença de transmissão aérea, facilitada em ambientes de pouca ventilação e iluminação, e encontra nos ambientes superlotados dos presídios condiçóes muito favoráveis para a infecção dos detentos.

A TB é uma doença infectocontagiosa que, em que pese ter documentada sua incidência desde a antiguidade, continua a infectar a humanidade nos dias atuais ${ }^{2}$. A prevalência da TB nos presídios não se limita apenas aos detentos, afeta também a comunidade com a qual se relacionam: familiares e funcionários dos presídios, durante e após a detençãa ${ }^{5}$.

Diante do exposto, este estudo objetivou verificar, através de uma revisão de literatura, as principais razões dos casos de TB nos presídios brasileiros.

\section{Materiais e métodos}

Para a realização desta pesquisa, foi adotado o sistema de revisão sistemática, ou seja, a busca de dados já publicados em bases de dados. Diante dessa opção, realizaram-se buscas, em setembro de 2014, nas bases de dados Periódicos Capes e Bielefeld Academic Search Engine (BASE). Nessas bases de dados, os termos utilizados foram "tuberculose", "presídio" e "brasileiro", inseridos no DeCS (Descritores em Ciências da Saúde).
Para a seleção dos artigos encontrados, os seguintes critérios foram utilizados: 1) somente seriam utilizados estudos que abordassem os descritores selecionados; 2) textos em português e; 3) artigos que fossem intervençóes realizadas em amostra brasileira. Os artigos que tratavam de realidades internacionais foram descartados pelos pares, já que não prestavam aos objetivos iniciais propostos, assim como revisôes sistemáticas e metanálises foram excluídas.

Encontrou-se, inicialmente, 34 textos nas bases de dados, sendo 9 encontrados nos Periódicos Capes e 25 na BASE. Na primeira avaliação desses 34 textos, foram encontradas e excluídas 14 referências idênticas. A seguir, foi realizada a leitura dos títulos e resumos, permanecendo, assim, 20 artigos para uma segunda avaliação.

Nessa nova etapa, tendo em vista o objetivo principal desta pesquisa mais 10 artigos foram excluídos. A exclusão desses artigos se deu uma vez que: 1 ) não apresentavam como objetivo principal a análise da TB nos presídios, ou 2) tinham como objetivo analisar somente os trabalhadores do presídio, não se ocupando dos encarcerados, ou 3) tratavam de temas genéricos, como saúde, fazendo pequena referência específica à $\mathrm{TB}$, ou 4) tratavam de realidade estrangeira, ou 5) não foi possível encontrar o trabalho completo.

$\mathrm{Na}$ leitura final dos artigos, foram excluídos outros 2 textos, por tratarem da relação entre TB e HIV nos presídios brasileiros, o que não é, de fato, objetivo desta pesquisa. Dessa forma, restaram 8 textos.

A Figura 1 a seguir demonstra o fluxograma relativo às etapas de seleção dos artigos.

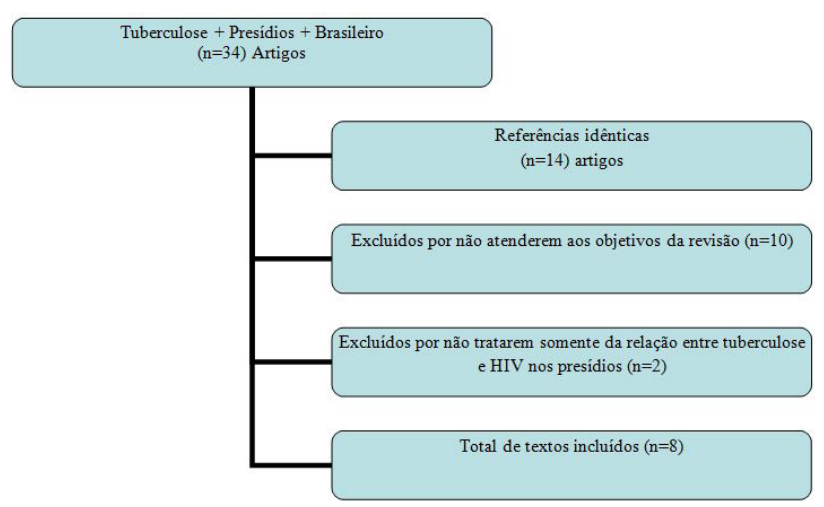

Figura 1: Esquema representativo do procedimento de seleção dos artigos para análise sistemática.

\section{Resultados}

O Quadro 1 demonstra os artigos selecionados por autor, participantes da amostra e o número de infectados por estudo. 
Quadro 1: Caracterização dos estudos selecionados.

\begin{tabular}{|c|c|c|}
\hline Autor & Amostra & Número de infectados \\
\hline Souza et al. ${ }^{4}$ & $\begin{array}{c}7 \text { apenados, infectados com } \\
\text { TB }\end{array}$ & $\begin{array}{l}\text { Compóe-se por sequências discursivas de referência, em dois principais blo- } \\
\text { cos, os quais reúnem formaçóes discursivas relacionadas e interpenetradas: } \\
\text { (1) A TB nas penitenciárias: a saúde aprisionada e; (2) Atraso no diagnósti- } \\
\text { co da TB: vivências do doente apenado. }\end{array}$ \\
\hline Oliveira e Cardoso 5 & 4.293 detentos & $\begin{array}{l}\text { Observou-se um pico de incidência da TB em } 1994 \text { (1.397,62 notifica- } \\
\text { çóes em } 100 \text { mil indivíduos). Menor taxa observada em } 1999 \text { (559,04). A } \\
\text { maioria dos presidiários não tinha realizado tratamentos prévios }(75,4 \%) \text {. } \\
\text { O abandono de tratamento chegou a } 49 \% \text {. Houve cura em apenas 20,8\% } \\
\text { dos casos. }\end{array}$ \\
\hline Nogueira e Abrahão ${ }^{6}$ & $\begin{array}{l}932 \text { detentos de } 9 \text { distritos } \\
\text { policiais }\end{array}$ & $\begin{array}{l}601 \text { detentos infectados }(64,5 \%) .55,1 \% \text { entre os detentos primários e } \\
75,6 \% \text {, entre os detentos reincidentes. } 57,1 \% \text { entre os detentos com tempo } \\
\text { de prisão inferior a } 60 \text { dias e } 64,4 \% \text {, entre os detentos com tempo de prisão } \\
\text { de } 60 \text { a } 180 \text { dias. } 70,1 \% \text { entre os detentos com tempo de prisão de } 181 \text { a } \\
365 \text { dias. } 74,4 \% \text { entre os detentos com tempo de prisão superior a } 366 \text { dias. }\end{array}$ \\
\hline Ferreira Júnior $^{7}$ & $\begin{array}{l}141 \text { detentos; } 115 \text { servi- } \\
\text { dores lotados na unidade } \\
\text { prisional; } \\
250 \text { servidores da rede } \\
\text { pública de saúde }\end{array}$ & $\begin{array}{l}\text { Diferenças significantes quanto ao conhecimento dos sintomas da TB entre } \\
\text { detentos e funcionários do presídio nas variáveis: tosse há mais de duas } \\
\text { semanas, tosse com catarro, tosse com sangue, náusea, febre, cansaço, dor } \\
\text { no peito, perda de peso, falta de ar e outros sintomas não relacionados à TB } \\
\text { ( } \mathrm{p}<0,001 \text { ). Quando questionados sobre "quem pode pegar TB" } 69,5 \% \text { dos } \\
\text { detentos referiram qualquer pessoa e para } 23,4 \% \text {, pessoas que se alimentam } \\
\text { mal e as que convivem com os doentes. Entre os funcionários do presídio } \\
86,9 \% \text { responderam que qualquer pessoa pode pegar TB e } 13,9 \% \text { citaram } \\
\text { idosos e fumantes. Na rede pública de saúde, } 98,4 \% \text { afirmaram que qual- } \\
\text { quer indivíduo pode pegar TB. As respostas diferiram significativamente } \\
\text { (p<0,001). A diferença foi verificada no item "tratamento com supervisáo } \\
\text { médica”, sendo de } 41,8 \% \text { entre detentos e } 76,5 \% \text { em funcionários do } \\
\text { presídio ( }<<0,001 \text { ). }\end{array}$ \\
\hline Vitti Junior $^{8}$ & $\begin{array}{l}17 \text { Unidades Prisionais de } \\
\text { São Paulo na área de Bauru, } \\
\text { SP }\end{array}$ & $\begin{array}{l}\text { O coeficiente de prevalência para o conjunto das UP foi de 528,7 casos por } \\
\qquad 100 \text { mil detentos. }\end{array}$ \\
\hline Rossi $^{9}$ & $\begin{array}{l}\text { População de detentos de } 7 \\
\text { unidades prisionais }\end{array}$ & $\begin{array}{c}\text { Incidência de } 1065,6 \text { por } 100 \text { mil entre os detentos e } 48,2 \text { por } 100 \text { mil } \\
\text { entre os náo detentos. }\end{array}$ \\
\hline Pereira et al. ${ }^{10}$ & $\begin{array}{l}\text { Incluiu } 386 \text { detentos em } \\
\text { regime fechado e } 159 \text { deten- } \\
\text { tos do regime semiaberto }\end{array}$ & $\begin{array}{l}\text { Um total de } 20,6 \% \text { foi considerado sintomáticos respiratórios. Entre estes a } \\
\text { prevalência de TB na população estudada foi de 1,9\% (1898 / 100.000). }\end{array}$ \\
\hline Macedo, Macedo e Maciel ${ }^{11}$ & $\begin{array}{l}\text { População carcerária do } \\
\text { estado do Espírito Santo }\end{array}$ & $\begin{array}{c}\text { Taxa de incidência de } 1962,6 \text { por } 100 \text { mil presos. O sexo masculino apre- } \\
\text { sentou maior incidência, assim como a faixa etária de } 25 \text { a } 36 \text { anos. Sobre o } \\
\text { desfecho dos casos, destaca-se que } 167(65,3 \%) \text { pacientes tiveram alta por } \\
\text { cura, ocorrendo dois óbitos durante o período, sendo a taxa de mortalidade } \\
\text { por TB de } 11,7 \text { por } 100 \text { mil presos. }\end{array}$ \\
\hline
\end{tabular}

\section{Discussão}

De um modo geral, os estudos que tiveram por objetivo analisar a incidência de TB nos presídios brasileiros, constataram que grande parte da população carcerária está infectada. Além disso, há relação entre a infecção e o tempo de encarceramento. Nogueira e Abrahão ${ }^{6}$ constataram que do total de 932 presos entrevistados, entre março de 2000 e maio de 2001, 601 estavam infectados, ou seja, $64,5 \%$ do total de encarcerados pesquisados.

No mesmo sentido, em estudo efetuado entre junho e novembro de 2010, que avaliou 386 detentos em regime fechado e 159 detentos do regime semiaberto, Pereira et al. ${ }^{10}$ verificou que a prevalência da TB foi de 1.898 para cada 100 mil encarcerados. Macedo, Macedo e Maciel ${ }^{11}$, estudando a população carcerária do estado do Espírito Santo no período de julho de 2009 a julho de 2010, apontam uma taxa de incidência de 1962,6 por 100 mil presos.

Outra pesquisa, realizada por Rossi ${ }^{9}$ com a população de detentos de 7 unidades prisionais da regiáo de Presidente Prudente, nos anos 1998 (1.515 detentos) e 2002 (5.275 detentos), aponta que a incidência da TB entre os encarcerados foi de 1065,6 por 100 mil entre os detentos . 
A taxa de prevalência elevada de TB, acima de 1.000 por 100 mil indivíduos, também foi verificada por Oliveira e Cardoso ${ }^{10}$ quando pesquisaram 4.293 detentos dos quatro presídios que constituem o complexo penitenciário da regiáo de Campinas, SP, no período de 1993 a 2000. Os autores supracitados verificaram uma incidência de TB que em seu maior número de infectados foi de 1.397,62 por 100 mil indivíduos, em 1994, e em seu menor número de infectados 559,04 por 100 mil indivíduos em 1999.

Sobre este menor número de infectados em 1999, a pesquisa mostra que náo foi observada uma tendência definida de crescimento ou redução, e as taxas observadas podem refletir falhas na notificação, bem como a demora na detecção de novos casos, problemas agravados por várias rebelióes durante o período.

Vitti Junior ${ }^{8}$ aponta que, durante a pesquisa, 109 detentos estavam em tratamento para TB. O coeficiente de prevalência para o conjunto das UP foi de 528,7 casos por 100 mil detentos. Todos os casos eram de TB pulmonar.

Este foi o menor número de infecçóes por TB registrado nas pesquisas, e pode estar associado ao fato de que nas unidades prisionais estudadas por Vitti Júnior ${ }^{8}$ como prevençáo é feito um controle de contatos entre companheiros de cela, mas não entre os funcionários da segurança. Adota-se isolamento dos casos suspeitos e dos confirmados no início do tratamento, bem como são desenvolvidas atividades educativas e de conscientização nos momentos de busca ativa periódica. Observou-se que, de forma geral, as equipes de saúde seguem a maior parte das normas e recomendaçóes, com maior envolvimento dos profissionais de enfermagem.

Dessa forma, é evidenciado nesse momento que os altos números de infecçẫo por TB foram encontrados em todas as pesquisas realizadas. É importante salientar o fato de as pesquisas serem realizadas em períodos diferentes, demonstrando que a infecção pela doença é contínua e nos presídios brasileiros.

Nogueira e Abrahão ${ }^{6}$ apresentam dados relevantes, no sentido de apontar diferença de incidência de infecção entre detentos primários e reincidentes. Entre os detentos primários, $55,1 \%$ estavam infectados, enquanto entre os detentos reincidentes $75,6 \%$ estavam infectados.

Pequena diferença foi encontrada pelos autores, quando analisado o tempo em que estavam encarcerados os infectados. Verificou-se que entre os presos com tempo de prisão inferior a 60 dias, $57,1 \%$ estavam infectados, e entre os presos com tempo de prisão de $60 \mathrm{a}$ 180 dias, $64,4 \%$ estavam infectados.

$\mathrm{Na}$ medida em que o tempo de prisão aumenta, progressivamente, aumenta-se o número de presos infectados pela TB. Entre os presos com tempo de prisão de 181 a 365 dias, 70,1\% estavam infectados, e entre aqueles cujo tempo de prisão superava 366 dias, $74,4 \%$ deles estavam infectados.

O estudo ainda apresenta um cruzamento de informaçóes pesquisadas, indicando que entre os 506 detentos primários entrevistados, 134 estavam presos há menos 60 dias e $40,3 \%$ deles estavam infectados; 180 detentos estavam presos entre 60 e 180 dias e $64,4 \%$ estavam infectados; 139 detentos estavam presos entre 181 e 365 dias e $67,6 \%$ estavam infectados; e 53 estavam presos há mais de 366 dias, e 62,3\% estavam infectados.

Sobre os presos reincidentes, apontaram que entre os 426 detentos, 146 estavam presos há menos 60 dias e $72,6 \%$ estavam infectados; 163 detentos estavam presos entre 60 e 180 dias e $75,5 \%$ estavam infectados; 92 detentos estavam presos entre 181 e 365 dias e $73,9 \%$ estavam infectados. Da análise dos dados, é possível identificar como um fator de risco de infecção por TB, o tempo de permanência do indivíduo na prisão e o retorno à prisão.

No mesmo sentido, nos dados encontrados por Vitti Junior $^{8}$ que considerou o regime de cumprimento de pena, o maior número de infectados encontrava-se no regime fechado, no qual o encarcerado permanece recolhido na maior parte do tempo (88\%) e apenas $12 \%$ no semiaberto, em que há a possibilidade de trabalho comum durante o dia.

Pereira et al. ${ }^{10}$ também evidencia que a média de tempo de encarceramento entre os casos de TB foi de 4,3 anos nos casos pesquisados. Assim, concluíram que o tempo de encarceramento está associado com um incremento considerável do risco de contaminação com $\mathrm{TB}$, latente e ativa.

Analisando os dados sobre a cura da doença, Oliveira e Cardoso ${ }^{5}$ apontaram que a maioria dos presos não sabia ou não tinha realizado tratamentos anteriores $(75,4 \%)$. Ainda, não foi possível obter informações acerca do encerramento do tratamento para $114(31,8 \%)$ pacientes, mostrando a precariedade da vigilância da TB no sistema penitenciário. Dentre os presos cujos dados estavam disponíveis, apenas 20,8\% foram considerados curados.

Em conclusão diferente, Macedo, Macedo e Maciel ${ }^{11}$ demonstram que $65,3 \%$ dos pacientes tiveram alta por cura e, por fim, evidenciam que a taxa de mortalidade é de 11,7 por 100 mil presos. Outra pesquisa, realizada por Rossi ${ }^{9}$, evidencia o fato de que o tratamento supervisionado dos doentes foi realizado em apenas $25 \%$ dos casos, com uma taxa de cura inferior a $70 \%$, dado muito próximo ao encontrado por Macedo, Macedo e Maciel $^{11}$.

Há pouca informação sobre a TB nos presídios. Os resultados demonstraram muitos conceitos equivocados sobre a transmissão, sintomas, tratamento e cura da TB, 
bem como na transmissão do HIV/Aids entre os três grupos pesquisados. $\mathrm{O}$ restrito acesso dos detentos às várias fontes de informação, como TV, rádio, e internet, permite que eles tomem conhecimento sobre essa doença apenas por meio dos poucos folhetos e cartazes que chegam até as celas? ${ }^{7}$.

Aponta o estudo que 76,6\% dos detentos e 63,5\% dos funcionários do presídio pesquisado referiram não terem recebido informaçóes sobre a $\mathrm{TB}$ na unidade prisional, e detentos $(79,4 \%)$, funcionários do presídio $(63,5 \%)$ e rede pública de saúde $(58,4 \%)$ responderam que náo se sentem bem-informados sobre a tuberculose e que desejam receber mais informaçóes sobre a doença.

Nesse aspecto, é importante destacar que a desinformação quanto à infecção de TB é tão alta quanto sua taxa de infecção nos detentos, conforme os dados levantados. Souza et al. ${ }^{4}$ pesquisaram, em uma instituiçấo hospitalar de referência, o tratamento da TB no estado da Paraíba, envolvendo sete apenados infectados. $\mathrm{O}$ estudo analisou as causas de atraso no diagnóstico da TB no sistema prisional, segundo a experiência do doente apenado, por meio de entrevista semidirigida. Concluíram que o atraso no diagnóstico da TB dentro do presídio relaciona-se à naturalização da desassistência ao sujeito preso, à interpretação do presídio como um lugar de morte e sofrimentos, o que se amolda aos resultados encontrados nas pesquisas referidas.

Isso vai ao encontro da conclusão de Rossi ${ }^{9}$ que aponta que o elevado coeficiente de TB encontrado entre os presidiários denuncia as precárias condiçóes de vida deles. Assim, os resultados encontrados destacam o grande número de infectados e a baixa informação sobre a doença, fato que evidencia a precária situação da prevenção da TB, com a baixa qualidade no atendimento dos infectados.

\section{Conclusão}

Mediante os estudos analisados foi possível verificar que existem altas taxas de infecção por TB nos presídios brasileiros e que a infecção está relacionada com o tempo de permanência na prisão. Além disso, é nítido na literatura estudada que a desinformação quanto à infecção de TB é tão alta quanto à taxa de infecção de detentos, além da baixa qualidade no atendimento do encarcerado infectado.

Por fim, os estudos pesquisados apresentam que esse quadro de baixa informação, altos números de infecção e baixa qualidade de atendimento podem se relacionar à naturalização da desassistência ao sujeito preso, à interpretação do presídio como um lugar de morte e sofrimentos, e do detento como um indivíduo cuja vida não precisa ser protegida pelo Estado.

\section{Referências}

1. Capez F. Curso de direito penal: parte geral. $14^{\mathrm{a}}$ ed. São Paulo: Saraiva; 2010.

2. Zanotto AB, Bertani BC. Monitoramento eletrônico: uma possibilidade de pena alternativa à prisão. Destaques Acadêmicos, 2013;5(2).

3. Pedrosa CMS, Rocha EMM. Aspectos clínicos e epidemiológicos da leishmaniose visceral em menores de 15 anos procedentes de Alagoas, Brasil. Rev Soc Bras Medicina Tropical. 2004; 37(4):300-4.

4. Souza KMJ, Villa TCS, Assolini FEP, Beraldo AA, França UM, Protti ST, Palha PF. Atraso no diagnóstico da tuberculose em sistema prisional: a experiência do doente apenado. Texto Contexto Enferm. 2012;21(1):17-25.

5. Oliveira HB, Cardoso JC. Tuberculose no sistema prisional de Campinas, São Paulo, Brasil. Rev Panam Salud Pública. 2004;15(3):194-9.

6. Nogueira PA, Abrahão RMCM. A infecção tuberculosa e o tempo de prisão da populaçáo carcerária dos Distritos Policiais da zona oeste da cidade de São Paulo. Rev Bras Epidemiol. 2009;12(1):1-8.

7. Ferreira Júnior S. Conhecimento, atitudes e práticas sobre tuberculose e HIV/Aids em prisóes e no serviço público de saúde. [Dissertação de Mestrado em Saúde Coletiva]. Campinas: Universidade Estadual de Campinas; 2011.

8. Vitti Júnior W. O controle da tuberculose nos presídios: atuação das equipes de saúde na região (DRS VI) de Bauru/ SP. [Tese de Doutorado]. Botucatu: Universidade Estadual Paulista Julio Mesquita Filho; 2013.

9. Rossi ZO. A tuberculose pulmonar nos presídios da região de saúde de Presidente Prudente - SP, DIR XVI - 19982012. [Dissertação de Mestrado]. Botucatu: Universidade Estadual Paulista Julio Mesquita Filho; 2006.

10. Pereira CC, Borges TS, Daronco A, Valim ARM, Carbeiro M, Becker D, Possuelo LG. Prevalência de sintomáticos respiratórios e tuberculose ativa em uma penitenciária do Sul do Brasil. Rev Epidemiol Control Infect. 2013;3(3):99-104.

11. Macedo LR, Macedo CR, Maciel ELN. Vigilância epidemiológica da tuberculose em presídios do Espírito Santo. Rev Bras Promoc Saúde. 2013;26(2):216-22.

\section{Como citar este artigo:}

A incidência de tuberculose nos presídios brasileiros: revisão sistemática. Rev. Aten. Saúde. 2016;14(47): 84-88. 